almost up to the groin; the pulse quick and irregular, and the patient is very nervous and irritable. Twelve leeches were ordered to be applied to the knee; and ammonia combined with salines and opium were likew ise preseribed. The leeches afforded some relief, and they were repeated several times, calomel being also administered. Under this treatment the swelling began to abate, the glazed appearance of the part disappeared, and only one hard point was left under the ham; yet the patient began to complain of a darting pain through the joint. He continued to experience much suffering, when, about twelve days after admission, Mr. Hawkins detected fluctuation at the internal part of the knee, where a round red spot was observed. A puncture was made, but no purulent matter discharged, though the opening would be useful for the ready exit of deep-seated matter. Poultices and subsequently blisters were applied; the patient was well supported by tonics and stimuli, and about twenty days after the puncture, the joint having gradually increased in size, and the constitutional symptoms become rather severe, matter was noticed to come away in the poultice. Even at that time, however, pressure of the tibia against the condyles of the femur did not give great pain. Mr. Hawkins soon found it necessary to enlarge the opening, in order to facilitate the evacuation of the pus; a little hæmorrhage took place subsequently; this was, however, easily arrested, but the probe being now passed through the wound, came in contact with the head of the tibia. On the 2nd of April, almost two months after admission, the tongue had become brown and dry, the pulse intermittent at 112, the pain excessive, and the discharge profuse and sanguineous; under these circumstances Mr. Hawkins, having consulted with his colleagues, proposed amputation, which was accepted after a little hesitation.

Mr. Hawkins removed the limb on the 4 th of April, at about the lower third of the femur, by the circular operation; very little blood was lost, no less than eighteen ligatures being applied. We noticed how yery useful in such cases are the retractors which are used in this hospital. They are crescentic in form, and when applied above and below the division of the soft parts, completely encircle the bone, effectually shield the muscles from the contact of the saw, and afford to the latter a very useful lateral support. The spring forceps, with the ligatures hanging lightly in a noose, are likewise constantly used here, and they seem to present many advantages over the ordinary forceps, from the readiness and certainty with which, by their means, the vessels are secured by the operator, and tied by himself whilst the assistant is holding the handle of the forceps.

On examination of the knee, which was considerably enlarged, an extensive wound was found on the internal side, the margins of which looked very unhealthy; from this, dark and putrid pus exuded on pressure. This abscess communicated directly with the joint, and, passing under the ham, opened likewise on the other side of the knee, where it also run into the juint. Several abscesses had formed in the cellular tissue round the articulation, the ligaments, however, were not attacked; the cartilages were diseased in a great many places, and at the front part of the inner condyle the cartilage was quite gone, small fungous growths protruded from the bone, and these were easily detached. The cartilages of the tibia were loose, and the bones themselves carious, the cancellated structure was infiltrated with pus, and the head of the tibia easily cut with the knife. The ossenus structure of the femur was in the same state, and the synovial membrane soft and ulcerated in many parts. It was a matter of surprise to $\mathrm{Mr}_{\text {r }}$ Hawkins how such extensive destruction could have taken place in so short a time in a man of middle age. The patient progressed tolerably well until about fourteen days after the operation, when he had severe rigors; these recurred several times afterwards; and though tonies and stimuli were liberally administered, the patient sunk almost one month after the operation, though the stump was nearly healed up.

On a post-mortem examination, it was found that the flaps of the amputated thigh had united, with the exception of a small sinus. The right lung was congested, of a brownish red colour, and somewhat soft and friable, but crepitant, except in severa well-defined patches where grey hepatization was observed, and on incisions being made, pus flowed from numerous points : the left lung was similarly affected, but in a less degree, and the heart quite healthy. One or two small whitish patches, apparently the commencement of secondary abscesses, were found in the left kidney. The femoral vein, on the amputated side, immediately below Poupart's ligament, and three or four inches down the thigh, was blocked up by a collection of purulent matter, which was limited above and below by a plug of lymph, firmly adherent to the inner coat of the vessel. Still further downwards, from the point where the vessel passes beneath the sartorius to the stump, the vein was filled with dirty-coloured pus. The profunda and saphena veins presented nothing remarkable. The fascia investing the left iliacus muscle was distended, and formed a portion of the walls of an abscess occupving the substance of the iliacus muscle; the greater part of the latter, almost to its insertion into the lesser trochanter, was in a gangrenous condition. A communication through the capsular ligament existed between the lastmentioned abscess and the cavity of the hip-joint, which was filled with pas, but the cartilages and the ligamentum teres were sound.

From the progress of this case, and the appearance presented by the knee-joint after amputation, it would appear that the inflammatory process first commenced in the cellular tissue around the joint, and that the synovial membrane, cartilages, and bones, were subsequently implicated. One reason for supposing that the abseess was formed in the cellular tissue external to the synovial membrane, and then penetrated it, is, that when the patient was first admitted, no pain was experienced when the articular surfaces of the tibia were pressed against those of the femur; but when the joint was moved laterally, the pain was very acute. Besides, swelling was here the first symptom, and it was likewise tolerably firm. The tumefaction, according to Mr. Wickbam, may last several months before severe constitutional symptoms set in, but here six weeks were sufficient; and it is but fair to conjecture that the intemperate habits of the patient, as we stated above, had a powerful influence on this difference. Nor can it be doubted, that those habits had a large share in the production of the phlebitis which eventually destroyed him.

\section{Royal Free Hospital.}

Retention of Urine; Puncture of the Bladder through the Rectum. (Under the care of Mr. GAY.)

There are some points of practice whereon surgeons are not quite agreed, and the management of obstinate cases of retention of urine is one upon which opinions differ in a very marked degree principally as regards the time when an artificial outlet should be made for the escape of the urine, and the portion of the urinary organs which should be punctured for that purpose. Every surgeon will, of course, endeavour by leeching, warm baths, and aperients, to obtain a natural evacuation of urine, or at least facilitate the passage of a catheter; and we had an opportunity of reporting a case, under the care of Mr. Tatum at St. George's Hospital, where efforts of this kind were crowned with success (See The LaNCET, June 22, 1850, p. 756.) But when distention becomes dangerous, the question arises whether we should puncture either the membranous portion of the urethra behind the stricture (Sir A. Cooper), or make a free opening in the perinæum directly over the obstructed part (Liston), or perforate the bladder through the rectum. Mr. Gay adrocates the latter practice, and bas lately been very successful in a case of retention of urine, of which we shall attempt to give an outline.

A labourer, forty-one years of age, was brought into the hospital on the 2nd of May, labouring under very distressing symptoms of retention of urine. The patient had been subject to stricture for many years; bougies had been passed at various periods; but the stream of urine had become very small, and occasionally degenerated into a dribble. On the night immediately preceding his admission, he found himself, after a debauch, unable to pass any urine; but as he was intoxicated, he went to bed, and slept until the morning. On awaking, the retention continued, and he was brought to the hospital.

The bladder, as may be easily imagined, was much distended, the patient tormented with a constant desire to evacuate it; the tongue thickly furred, the pulse quick, the thirst extreme, and the heat of skin very great. A brisk purgative was at once administered, leeches applied to the perinæum, and the patient placed in a warm bath. Mr. Jackson, the house-surgeon, then tried to pass a catheter, but could not succeed, even with the smallest size. After the bowels had been well opened, a good dose of opium was given, and bougies and elastic catheters tried again, but without effect. At one o'clock in the afternoon the bladder had become much more distended; and no prospect of immediate relief by the usual remedies being anticipated, Mr. Gay was sent for.

After examining the patient, and conferring with his colleague, Mr. Wakley, Mr. Gay determined that no time should be lost, and at once punctured the bladder from the rectum. A large quantity of urine passed, the canula was withdrawn, and the patient instantly dropped off into a sound sleep. An antimonial saline draught, with tincture of opium, was ordered to be given every four hours. In the evening the patient expressed a desire to pass his urine, and he did so, but with his ordinary amount of difficulty. He continued to evacuate his bladder at intervals during the night, and from that time his recovery was so rapid, 
that four days after admission, he left the hospital to resume his work, and was desired to attend, as an out-patient, to have the narrowed canal of the urethra gradually dilated.

This is a type of the majority of cases of retention of urine which apply at the hospital for relief; and Mr. Gay is strongly of opinion that similar treatment, instead of that which is too often pursued-viz, cutting down on the seat of the stricture,would be atteuded almost invariably with similar success. 'The condition of the urethra, in cases Jike the preceding, is of a temporary character, and as it is brought about, with few exceptions, by excesses, it is to be remedied by those means which are calculated to reduce the inflammatory action which is generally combined with spasm. The time required for overcoming this state of urethra is, however, too long, while the bladder remains unrelieved, and the question then presents itself-Which is the simplest and least dangerous method of evacuating the urine?

Mr. Gay stated that, notwithstanding the objections which have been brought against the operation of puncturing through the rectum, he had not met, in his experience, any unfavourable results from this practice. He had operated on persons of different ages, and on one person in particular, under the most unpromising circumstances, and nevertheless, not a single bad symptom had ever followed. Mr. Gay believed that such bad likewise been the fact in the practice of other surgeons. He therefore unhesitatingly recommended this method as being vastly superior to incisions into the perinæum.

Should the stricture be of such an obstinate character that the relief which was obtained in the preceding case does not immediately follow, and the bladder again become distended, Mr. Gay would prefer, especially if there were the slightest prospect of effecting a passage by the nse of bougies and other treatment, puncturing the bladder again and again to cutting down on the stricture; and he is convinced that there are very few strictures, in the condition alluded to, which do not admit of cure by a well directed course of treatment and use of instruments.

The dangers attending the other modes of relieving the bladder are very great, and the fatality frightful. Such operations on individuals whose constitutions have been impaired by irregularities and excesses of all kinds (and these are the very persons who are generally subjected to this treatment) are il borne, and should if possible be avoided. Mr. Gay believes the time will come, and that shortly, when the perinæal section will be very rarely performed, and the puncture from the rectum be, so far as operations are concerned, the rule of practice.

In the case before us, no urine passed per rectum after the withdrawal of the canula, nor has such a circumstance occurred in any case which Mr. Gay has seen. The puncture of the trocar does not produce any loss of substance, but three valves are formed on the recto-vesical septum which close the aperture when the instrument is withdrawn.

\section{LONDON HOSPITAL. Collodion in Erysipelas.} (Under the care of Mr. LUEE.)

We have to direct the attention of our readers to a new topical application in cases of exysipelas, the beneficial effects of which are now placed beyond a doubt. The substance in question is colledion, which has been found so serviceable in many respects, not the least being its capability of arresting the hæmorrhage from leech bites in children. Mr. Luke considers that collodion applied to the inflamed surface in erysipelas, acts by compressing the capillaries of the skin, and thereby contributes materially in relieving those vessels.

He was induced to make use of this liquid in the manner described, on the suggestion of Mr. Bird, the author of the Jacksonian Essay on Erysipelas, which lately gained the prize; and Mr. Luke has had occasion to be highly satisfied with the results he has obtained, both in hospital and private practice. Several cases of erysipelas have been thus treated in Mr. Luke's wards, it will, however, be sufficient to report one of these, kindly furnished by Mr. Peete, to show how fully the application answers the purpose.

Amelia S., forty years of age, was admitted under the care of Mr. Luke, June 1, 1850, with acute inflammation of the neck, which, a week after admission, ended in abscess. This was opened, a large quantity of pus evacuated, and the patient went on very favourably for a week, when an inflammation of an erysipelatous character was observed to have invaded the upper part of the back. It extended from the neck to the first lumbar vertebra, including both scapula, and the inflammation had a distinctly defined margin.

Collodion was immediately applied by means of the finger to the whole surface, and to some little distance beyond it. The skin was much puckered by this measure, and the patient complained of the constringent effects of the collodion. Mr. Luke ordered the patient to have an allowance of wine, as she was rather depressed. (We may here state that most cases of erysipelas are treated in this hospital by large doses of stimulants, as brandy, wine, \&c. \&c.; and that this line of practice is generally followed by very favourable results. The type of the erysipelatous affection in charitable institutions is commonly of a very debilitated kind, and this fact would partially explain the necessity of supporting the patients by the stimulants just mentioned.)

In the case betore us, the collodion was repeated the following day ; and on the third, the erysipelas had entirely subsided in the part where it had first made its appearance. It, however, broka out afresh about the nose, lips, and eyelids; and a little lower down it extended from the edge of the wound made by the lancet to the whole ches!, implicating both mammæ. Patient complained of violent pain in her head; her eyelids were closed, and she had delirium at intervals, particularly at night, The collodion was applied, in the manner described above, to the whole chest and face; the hair was removed, and the head kept cool with a spirit lotion. These topical measures, combined with the administration of stimulants, proved extremely beneficial, and the patient improved rapidly. The collodion was applied daily for a week, and on the 24 th of June, ten days after the first onset of the erysipelas, the inflammation had quite disappeared, and the patient was declared convalescent.

A male patient was lately treated in the same manner for erysipelas, and the successful results were very quickly ob. tained. Mr. Luke has used the collodion very frequently in private practice : in one instance it was placed upon a young lady's face, excepting a small portion of the cheek, from which it peeled off. This part, soon afterwards, begun to look redder, and projected beyond the surface of the surrounding skin, being, in some degree, herniated. This circumstance showed very clearly how great must have been the pressure which was exercised by the fluid. Thus it would appear that the collo. dion fulfils two indications of an important kind: it protects the inflamed surface from the contact of the air, and it contributes, by the pressure it effects, in driving the blood from the distended capillaries.

\section{ftedrical Ẽorírtírs.}

\section{ROYAL MIEDICAL AND CHIRURGICAL SOCIETY.}

Tuesday, June 25, 1850.-The President in the Chair.

A Case of Ileus and Strangulated Hernia occorring in the same Indridual. By Sameel Solly, F.R.S., Senior Assistant-Surgeon to St. Thomas's Hospital.

TrE patient was a fine young man, aged twenty-one. Mr. Solly found him, at half-past ten A.M., writhing on the floor in great agony. He had an inguinal hernia on the right side. The account which he gave was, that the swelling and pain occurred simultaneously on going to the water-closet immediately after breakfast. About ten days previously he had obstinate constipation, for which he took some strong aperient medicine, which, when acting, produced a good deal of pain, and left considerable irritation of the bowels, that lasted some days the evacuations being tinged with blood; but this all passed away, and on the Sunday before the Wednesday on which he was seen by Mr. Solly he took a walk of fifteen miles without feeling any fatigue. On the Tuesday night he made a full supper of stewed beef, and on the Wednesday morning again ate of the same dish, and so heartily that he acknowledged to his friend that he had eaten too much. As he left his home after breakfast, at half-past eight A.M., and was descending the steps of his house, he complained to his friend of a violent pain in his belly, having at that time a swelling in the groin; this pain was so severe that he was obliged to ride up to town and by the time he reached his destination, in Leadenhallstreet, he was deadly pale, and his lips blue with pain. On his arrival he went to the water-closet, and passed some faces, and in doing so the swelling first appeared in the groin. He says it came down without any pain. The taxis proved un successful, and the hernia was so very sensitive, that he was removed to bed, and ordered a warm bath, and in the mean. time ice to be applied. In an hour's time, the ice having produced no effect, the taxis was again tried, but very gently, without avail. The warm bath was next used, but with the same result. It was now determined to operate, just four hours after the descent of the rupture. The external and in- 